\title{
ANÁLISE DA PAISAGEM PARA INTERPRETAÇÃO DO CONTEXTO AMBIENTAL DA ÁREA DO SÍTIO ARQUEOLÓGICO PIRACANJUBA, PIRAJU-SP
}

\author{
Larissa Figueiredo Daves $^{(\mathrm{a})}$, Neide Barrocá Faccio ${ }^{(\mathrm{b})}$
}

(a) Geógrafa e mestranda do curso de Pós-graduação em Geografia da Universidade Estadual Paulista - Campus de Presidente Prudente, larissadaves_@hotmail.com.br

(b) Livre Docente, Arqueóloga e Docente da Universidade Estadual Paulista - Campus de Presidente Prudente, nfaccio@terra.com.br

\section{Eixo: Geodiversidade, Geoarqueologia e Patrimônio Natural}

\begin{abstract}
Este artigo apresenta as contribuições da Geoarqueologia no estudo da paisagem em sítios arqueologicos. Neste caso, temos como discussão o padrão de assentamento do Sítio Arqueológico Piracanjuba. Trata-se de um sítio lito-cerâmico de Tradição Tupiguarani, localizado no Municipio de Piraju-SP, a jusante do Rio Paranapanema. Esse sítio foi encontrado no ano de 1990, durante a realização do projeto de Salvamento Arqueológico da Usina Hidrelétrica Piraju - ArqPiraju. Neste contexto, a área do sítio foi analisada a partir da presença das manchas pretas de solo antropogênico. Utilizamos os pressupostos das Ciências da Terra, particularmente Geomorfologia e Geologia, para interpretação da morfologia do relevo e da distribuição dos vestígios arqueológicos, a fim de investigar o padrão de assentamento guarani na área do sítio em tela.
\end{abstract}

Palavras-chave: Geoarqueologia, Análise da Paisagem, Solo antropogênico, Cerâmica Guarani.

\section{Introdução}

Desde sua institucionalização como ciência, a Geografia busca - enquanto eixo epistemológico central - a relação sociedade e natureza (SUERTEGARAY, 2009; CASSETI, 2009). Nesse âmbito, a paisagem temse mostrado uma categoria essencial ao debate relacional dessas duas categorias (PASSOS, 2003; 2006).

A paisagem se inscreve no espaço real e corresponde a uma estrutura ecológica bem determinada: mas ela só é "apreendida" e qualificada enquanto tal a partir de um mecanismo social de identificação e de utilização. A paisagem aparece cada vez menos como uma estrutura ecológica e social e cada vez mais como um processo de transformação, logo, como um fenômeno inscrito na história. Ela é uma interpretação social da natureza. E o método consiste, pelo menos em um primeiro tempo, em ir da sociedade para a natureza. (BERTRAND; BERTRAND, 2009, p. 221).

Desse modo, "analisar uma paisagem é, pois, aprender o real em diversas escalas" (CLAVAL, 2014, p. 65), caracterizando-a como realidade múltipla e analisando-a em diversas perspectivas, pois a paisagem é multidimensional e multiescalar, podendo sua dimensão ser funcional, simbólica, econômica, social e geoambiental. No caso de suas diversas escalas de análise, temos a espacial, temporal, local e 
comportamental. Assim, a análise da paisagem permite discutir o processo, os elementos geográficos e a forma como a sociedade, nesse caso o grupo Guarani, interferiu no ambiente onde viveu.

A paisagem nesse sentido é entendida como a criação da ação humana em conjunção de um ambiente social (como um meio), a sociedade (como uso do meio) e cultura (como a concepção sobre o meio). Assim, entendemos a Arqueologia como estudo da cultura material dentro de contextos socioculturais socioculurais documentados arqueologicamente (BOADO, et al. , 1989).

Desse modo, apresenta-se a análise da morfologia do relevo da área do Sítio Arqueológico Piracanjuba, a partir da descrição da paisagem, com base na metodologia da Geoarqueologia. O objetivo é o de mostrar a relação existente entre a localização do sítio arqueológico, a distribuição dos vestígios arqueológicos e o padrão de assentamento guarani na área do Sistema de ocupação indígena da área do Médio Paranapanema, lado paulista.

\subsection{Pressupostos teóricos}

A pesquisa arqueológica pode contribuir para a compreensão da formação do espaço e suas transformações pretéritas. Uma relação interdisciplinar entre a Geografia e Arqueologia permite analisar ambientes naturais do passado na sua relação com os grupos indígenas para evidenciar as razões que levavam esses grupos a estabelecerem assentamento em determinada área.

Butzer (1982) aborda que a Geoarqueologia, definida como "arqueologia realizada com a contribuição das Ciências da Terra", se articula de maneira interdisciplinar com outras ciências principalmente na interpretação dos contextos arqueológicos. Desde então, essa definição tem-se ampliado com informações críticas e empíricas em abordagens conceituais para analisar a paisagem habitada pelo homem em tempos pretéritos.

Trigger (2004) afirma que o uso de informações das geociências, como contributivas na construção da prática arqueológica, está na gênese da própria Arqueologia, enquanto área de conhecimento sistemática.

As ligações entre a Arqueologia e as chamadas disciplinas da paisagem parecem bastante concretas. De fato, o homem pré-histórico inseriu-se em contextos bastante complexos, "palcos" onde ele desempenhou papéis variados. Genericamente, os palcos identificam-se com o meio ambiente. Considerando-se as esferas geográficas que se entrelaçam e se complementam (atmosfera, litosfera, hidrosfera e biosfera), o homem pré-histórico, como participantes delas, não pode ser estudado fora do seu conjunto. (MORAIS, 1986, p. 64).

O uso do termo "Ciências da Terra" (ou Geociências) em lugar de Geologia (ou Ciências Geológicas) "não é arbitrariedade semântica, mas relaciona-se com o leque de disciplinas que as primeiras abarcam e que, na tradição universitária europeia, não estão incluídas nas Ciências Geológicas, como a Pedologia, a 
Geografia Física ou a Climatologia.” (WATERS, 1992, p. 3). Assim, o geoarqueólogo utiliza-se desse apetrecho metodológico quanto de outras disciplinas no âmbito geológico (Sedimentologia, Estratigrafia, Petrologia). (ANGELUCCI, 2003).

A geoarqueologia utiliza técnicas e abordagens da geomorfologia (estudo da origem e morfologia da forma de relevo), sedimentologia (estudo das características e formação de depósitos), pedologia (estudo da formação e morfologia do solo), estratigrafia (estudo da sequência e correlação de sedimentos e solos) e a geocronologia (o estudo do tempo em uma sequência estratigráfica) para investigar e interpretar os sedimentos, solos e formas de relevo em sítios arqueológicos. Desse modo, cada ciência fornece um componente essencial para o estudo dos sistemas ambientais, sendo fundamental a interdisciplinaridade em pesquisas arqueológicas. (WATERS, 1992).

A Geomorfologia tem contribuído para um maior relacionamento com diferentes campos do conhecimento científico especialmente relacionados às diferentes morfologias do relevo. A Arqueologia tem investigado a estrutura superficial da paisagem (AB'SABER, 1969), por meio da morfodinâmica e das relações morfogenéticas, a partir de subsídios de natureza cronológica. Segundo Casseti (1983) a "Geomorfologia, após ter passado por sucessivos estágios evolutivos que responderam por diferentes tendências, tem se estruturado a ponto de estabelecer uma metodologia própria que permite situar em diferentes linhas de pesquisa" (CASSETI, 1983, p. 2).

São fundamentais não apenas à própria geomorfologia, como também a certas ciências, como é o caso da arqueologia, que tem procurado além de justificar a posição geográfica dos sítios, uma melhor interpretação dos processos cronodeposicionais. Deve-se acrescentar que as evidências arqueológicas também se constituem em referenciais de importância à caracterização das estruturas superficiais em geomorfologia. (CASSETI, 1983, p.2)

As questões geoarqueológicas devem surgir a partir de uma consideração de variáveis em sistemas interativos entre sociedade e natureza (HASSAN, 1979). Nesse contexto, a Geomorfologia, ao estudar os processos intervenientes no modelado do relevo, a análise dos processos contemporâneos e sua distribuição espacial, proporciona analogias para a associação e compreensão do passado (GLADFELTER, 1977; 1981). Desse modo, os estudos dos vestígios arqueológicos por meio da aplicação de metodologias com base na Geomorfologia e Geologia são fundamentais para a interpretação do comportamento cultural de determinado grupo humano, uma vez que "o contexto geomorfológico e geológico do artefato completa informações, pois o objeto arqueológico é, de fato, remanescente de padrões de comportamento vividos em contextos ambientais pretéritos" (MORAIS, 1986, p. 66).

\section{MATERIAIS E METÓDOS}

DOI - 10.20396/sbgfa.v1i2017.1970 - ISBN 978-85-85369-16-3 


\section{1.Área de estudo}

O Sítio Arqueológico Piracanjuba está localizado a jusante do Rio Paranapanema, no Município de PirajuSP (Figura 1).

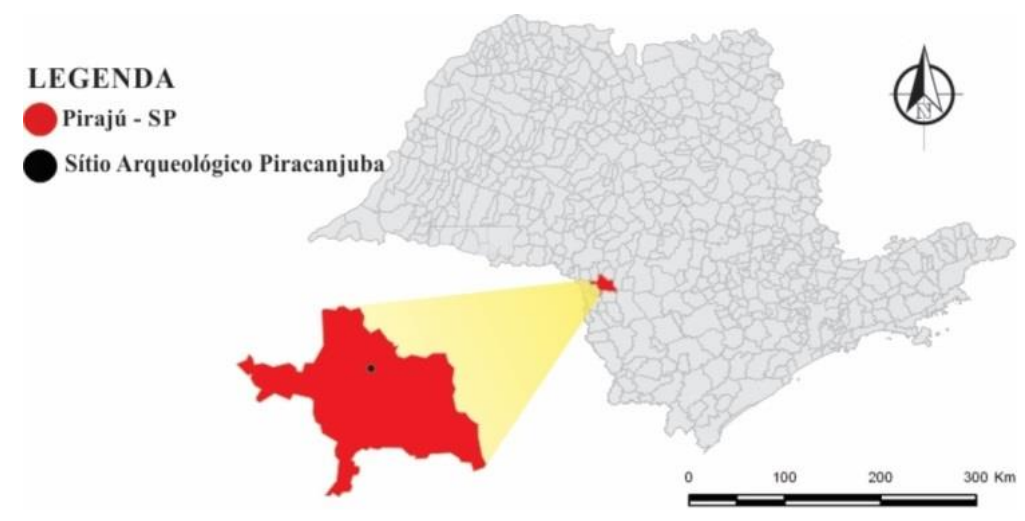

Figura 1: Localização do Sítio Arqueológico Piracanjuba, Piraju-SP.

As pesquisas sobre a área do Sítio Arqueológico Piracanjuba fazem parte do ProjPar (Projeto Paranapanema) implantado em 1968, sob a coordenação da Profa. Dra. Luciana Pallestrini, dentro do âmbito institucional do MAE/USP. Esse projeto direcionou os estudos das ocupações pré-históricas ao longo das margens do Rio Paranapanema, lado paulista (FACCIO, 2011).

O Rio Paranapanema estabelece a divisão fronteiriça entre os Estados de São Paulo e Paraná. Nasce na Serra de Paranapiacaba, com aproximadamente 900 m de altitude e deságua no Rio Paraná; percorre cerca de $500 \mathrm{~km}$ para receber como tributários os Rios Itararé, Pardo, Tibagi e Pirapó (ZIESLER; ARDIZZONE, 1979). O Rio Paranapanema é caracterizado como sistema de segunda grandeza ${ }^{1}$, a escala analisada teve como parâmetros a Geomorfologia e a hidrologia, caracterizando eventos culturais próprios de cada região, ligados pela variação interna de sua paisagem e de seus atributos ecológicos.

Segundo Ab’Saber (1969), a bacia de drenagem do Rio Paranapanema apresenta $109.6000 \mathrm{~km}$ de extensão, estando presente em três grandes unidades do relevo brasileiro: o Planalto Atlântico, a Depressão Periférica e o Planalto Arenítico Basáltico Ocidental. De acordo com o Instituto Geográfico e Geológico (1974), a região de Piraju, SP, é caracterizada pelo domínio dos derramamentos basálticos do final do Mesozoico, da Formação da Serra Geral.

Os grupos Guarani que habitavam os terraços do Rio Paranapanema migraram, desde a Amazônia, transitando por longo período pelas calhas e por afluentes de rios até chegar ao Rio Paraná (FACCIO,

1 De acordo com Strahler (1954), a classificação dos elementos de um sistema fluvial (hierarquia fluvial) tem como canais de primeira ordem ou grandeza são ligados diretamente à nascente; os sistemas de segunda ordem apresentam confluência de dois canais de primeira ordem e só recebem afluentes de primeira ordem; os sistemas de terceira ordem surgem da confluência de dois canais de segunda ordem, podendo receber afluentes de ordenação inferior, e a assim por diante. 
2011). A Geomorfologia da bacia do Rio Paranapanema, apresenta em seu relevo abundância de recursos como rochas de silexito $^{2}$, arenito silicificado, basalto e também a argila, facilitando para os grupos indígenas a obtenção de matéria-prima para a confecção de materiais líticos e cerâmicos.

\subsection{Procedimentos metodológicos}

Para fundamentação teórica da temática proposta, foram realizados levantamentos bibliográficos, com base em relatórios de campo e obras acadêmicas sobre arqueologia preventiva de sítios arqueológicos no Município de Piraju, destacando-se as obras de Morais (1979; 2010), Pallestrini (1981; 1982; 1984), Faccio (1992; 1998; 2011) e Caldarelli (1997).

A análise enfatizou a localização - compartimentação do relevo - e a datação de vestígios cerâmicos no perímetro do Sítio Arqueológico Piracanjuba, a fim de discutir o padrão de assentamento guarani. Foi realizada análise espacial intrassítio, cuja proposta priorizou a distribuição dos vestígios arqueológicos na área das quatro manchas pretas.

Carr (1984) aborda que a análise espacial intrassítio tem vários objetivos, tanto no nível inferencial, que leva em consideração a reconstrução e explanação dos comportamentos passados e atividades não observáveis e o nível operacional, das relações entre observações arqueológicas.

Nesse caso, tivemos como base o nível inferencial da análise espacial intrassítio realizado por duas razões: definir limites espaciais de áreas de atividades e definir a organização dos tipos de artefatos dentro do conjunto de ferramentas.

A tentativa de analisar a compartimentação topográfica do sítio arqueológico localizado e a paisagem, com base na aplicabilidade das bases geomorfológicas e interpretação de evidências arqueológicas, teve como metodologia os níveis de tratamento proposto por Ab’ Saber (1969).

O primeiro nível tem por objetivo compartimentar a topografia regional, a partir da relação das formas de relevo em cada um dos compartimentos, de modo a obter informações sistemáticas sobre a estrutura superficial da paisagem, baseadas nos elementos topográficos e morfológicos, ou seja, sobre os compartimentos e as formas de relevo. Esse primeiro nível busca uma caracterização da situação morfológico-espacial por meio de um plano horizontal.

O segundo nível procura explicar, pela sequência deposicional, a análise vertical das evidências cronogeomorfológicas da estrutura superficial da paisagem, tendo por base a análise dos processos

\footnotetext{
2 O arenito silicificado utilizado pelas populações pré-históricas do Vale do Paranapanema tem sua origem ligada a um extraordinário derrame de lava, resultante do vulcanismo neojurássico e o cretáceo da bacia do Paraná [...], acumuladas em depressão e fissuras do basalto, resultando em diques clásticos (arenito intrapino) (SUGUIO; FULFARO, 1974). O silexito e a calcedônia, normalmente encontrados nas proximidades dos morros residuais areníticos em blocos e depósitos coluviais de encostas, são minerais da classe dos silicatos, bastante comuns, pertencentes ao grupo do quartzo, que se formam a altas temperaturas e pressão (DANA, 1978).
} 
morfoclimáticos e pedogênicos. No terceiro nível, a análise fisiologia da paisagem tem por objetivo compreender os processos morfogenéticos a partir da dinâmica climática atual. Desse modo, os três níveis tornam evidente uma progressão contínua em termos de controle de campo, para descrever os processos morfogenéticos da área estudada (CASSETI, 1983).

De acordo com o autor, é evidente a aplicação dos dois primeiros níveis metodológicos para a Arqueologia, por "entender uma estreita vinculação entre os compartimentos topográficos e formas de relevo na eleição dos sítios e através dos fatores morfodinâmicos, a inumação por depósitos correlativos de evidências arqueológicas" (CASSETI, 1983, p. 3).

Desse modo, a análise da compartimentação topográfica e as formas de relevo presentes no sítio arqueológico devem ser compreendidas a partir dos dois níveis, sendo que:

O primeiro nível metodológico pode ser caracterizado a partir da prospecção arqueológica, oferecendo subsídios à justificativa da escolha dos sítios, não só quanto à posição estratégica, visando a uma possível defesa, mas principalmente como recurso disponível à sobrevivência: abrigo, água, alimento e materiais necessários à confecção de utensílios, indispensáveis à prática da sobrevivência. (CASSETI, 1983, p. 4).

Nesse sentido, a compartimentação topográfica é caracterizada como um referencial indispensável para a caracterização da área do sítio arqueológico, pois a análise da estrutura superficial procura observar o solo e os depósitos de cobertura vegetal presentes nas vertentes e interflúvios, de modo que formule uma análise do passado, utilizando-se como base o desfolhamento sistemático dos componentes epidérmicos da paisagem (CASSETI, 1983).

Casseti (1983) ainda relata que o estudo, a partir desses dois níveis, contribui para a compreensão da escolha da posição geográfica do sítio arqueológico, e ainda oferece elementos auxiliares para análise de evidências de coluvionamentos posteriores, pelos caracteres físico-químicos dos depósitos correlativos. Desse modo, a análise da estrutura superficial permite que o arqueólogo consiga comprovar os estudos cronogeomorfológicos, a partir da datação dos vestígios arqueológicos e dos geoindicadores com indícios de habitação em tempos pretéritos.

\section{RESULTADOS E DISCUSSÕES}

O sítio arqueológico apresenta grande quantidade de material arqueológico, principalmente o material cerâmico com decoração pintada policrômica, característica da cerâmica Guarani. Prous (2005) relata que esse tipo de cerâmica apresenta em sua pintura cores vermelhas, preta e branca (ou creme). A cerâmica 
XVII Simpósio Brasileiro

de Geografia Fisica Aplicada

I Congresso Nacional

de Geografia Física
OS DESAFIOS DA GEOGRAFIA FÍSICA NA FRONTEIRA DO CONHECIMENTO

Instituto de Geociências - Unicamp

Campinas - SP

28 de Junho à 02 de Julho de 2017

Guarani apresenta parede angular, antiplástico mineral e caco moído, pintura vermelha e preta sobre engobo branco (Figuras 2 e 3).
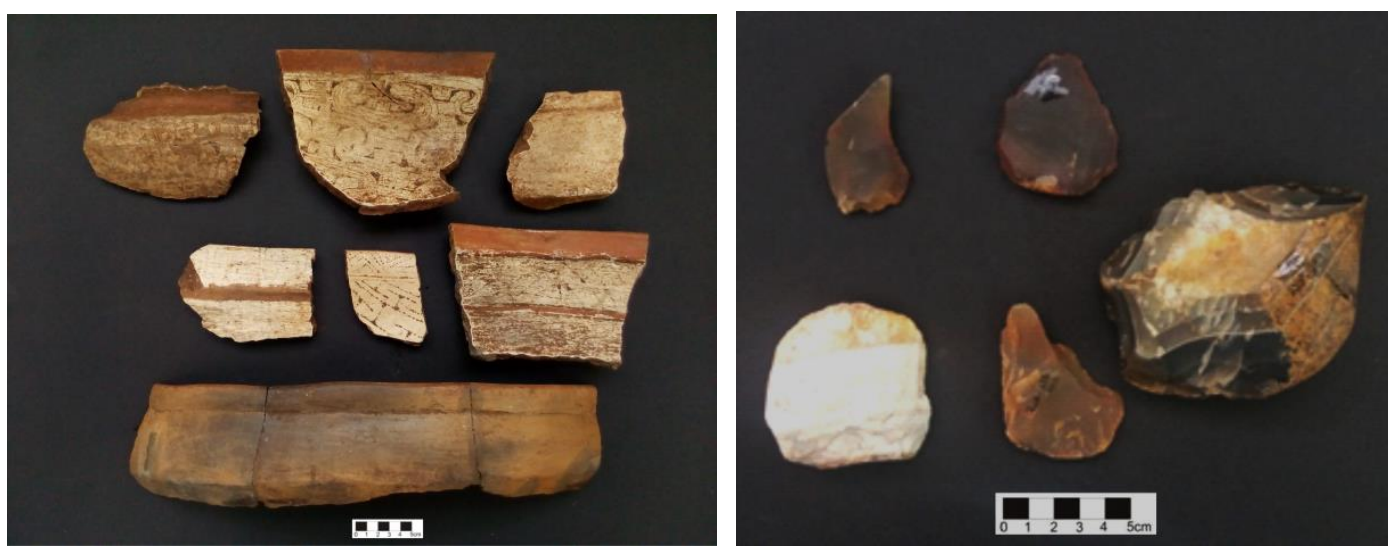

Figuras 2 e 3: Cerâmica Guarani policrômica e líticos lascados do Sítio Arqueológico Piracanjuba, Piraju -SP.

Além do material cerâmico, no sítio arqueológico foram evidenciados líticos lascados, como lascas, núcleos (Figura 3) e polidos como tembetás, machados, amoladores, calibradores; líticos lascados e vestígios faunísticos. De acordo com as datações obtidas por termoluminescência e carbono 14, o grupo Guarani habitou a área do sítio do século XIV ao XVII. O conjunto de vestígios encontrados neste sítio possibilita classificá-lo como remanescente de uma aldeia (GONZALEZ; PIEDADE, et. al., 2007).

As primeiras escavações arqueológicas na cidade de Piraju, SP, foram realizadas por Pallestrini (1968; 1969) nas áreas dos Sítios Alves, Camargo (PALLESTRINI; CHIARA, 1978), Nunes e Camargo 2, analisado por Morais (1988). Segundo Faccio (2011), nas áreas do baixo, médio e alto Paranapanema, os Guarani ocuparam terraços, quando o assentamento estava próximo ao Rio Paranapanema e de meia encosta de vertentes suaves e áreas de ápice de colina com a presença de um rio próximo ao local, quando distantes do Rio Paranapanema.

A paisagem característica da localização dos sítios arqueológicos mostra que fundos de habitação aparecem em cores escuras, realçadas pelo crescimento diferencial da vegetação. Outra característica relevante dos assentamentos é identificada pelo tamanho da aldeia, caso em que os geoindicadores trazem contribuições a respeito da distribuição dos vestígios no perímetro do sítio arqueológico (PROUS, 1992). Durante as escavações na área do Sítio Arqueológico Piracanjuba, foram identificadas quatro manchas de solo antropogênico, também conhecidas como manchas pretas, remanescentes de antiga aldeia de populações agricultoras pertencentes ao Sistema Regional de Ocupação Guarani (Figuras 4 e 5). 

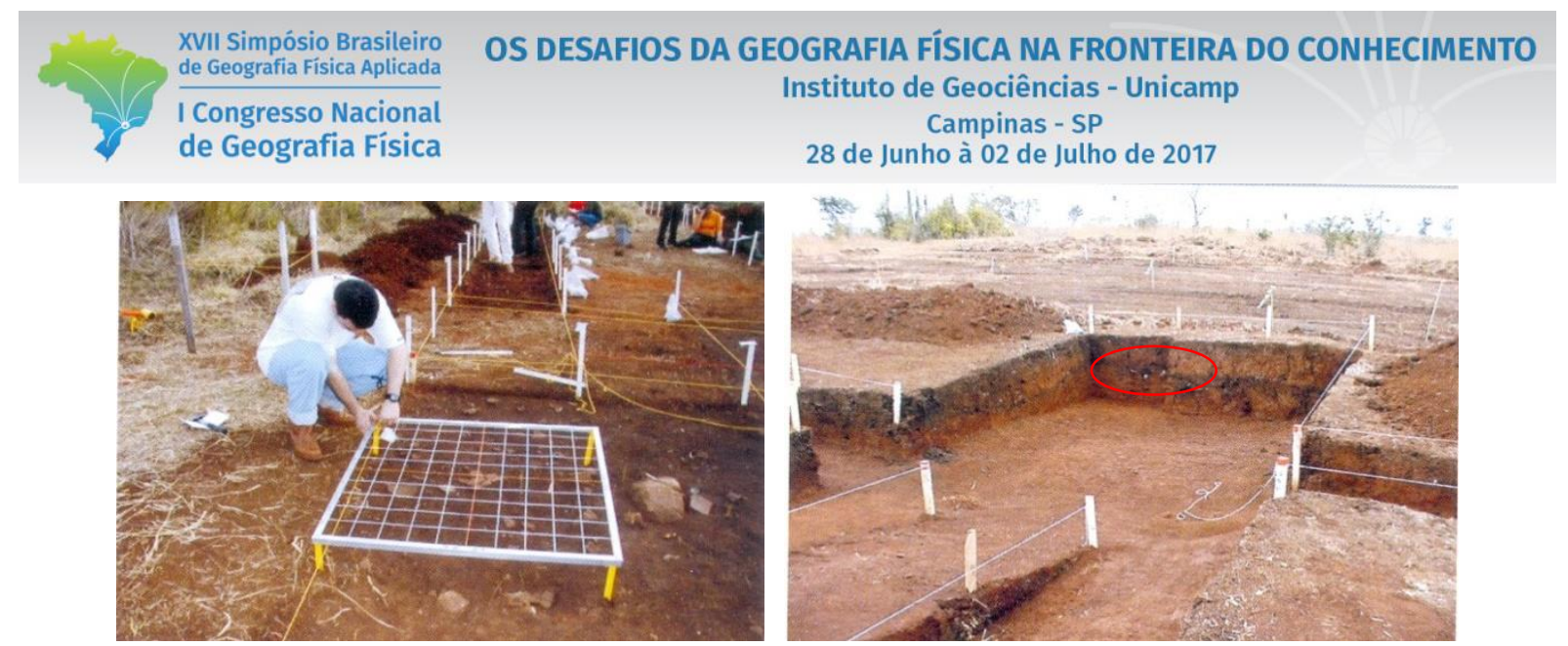

à 02 de Julho de 2017

Figuras 4 e 5: Escavação arqueológica do Sítio Piracanjuba, Piraju, SP. A coloração escura mostra a concentração de cerâmica e a presença de ter solo antropizado. Fonte: Morais (2006)

$\mathrm{Na}$ área das manchas escuras, encontram-se vestígios de combustão pouco estruturados, ao redor dos quais se concentra a maior parte da cerâmica (PANACHUK; CARVALHO; JÁCOME et. al. 2010). Os materiais orgânicos de cor escura encontrados nas manchas pretas são interpretados como fundos de habitação que costumam espalhar-se por um espaço de 120 a 150 metros de diâmetro. Segundo Faccio (2011), essas manchas pretas são evidências de antigas habitações que, depois de abandonadas, deixavam no solo as marcas de seu passado. Para Noelli (1993):

As "manchas pretas" podem ser caracterizadas como um contexto arqueológico bem definido no caso Guarani, podendo ser dividido em dois tipos distintos: a) estrutura de habitação; b) estruturas anexas com diversos fins, como processar alimentos (ralar, pilar, descascar, moquear, assar, cozinhar, etc, que também poderiam ocorrer nas de habitação), depositar, manufatura de objetos, lazer, etc. Essas definições estão apoiadas em informações etnográficas. (NOELLI, 1993, p. 77).

Morais (2006) relata que o núcleo de solo antropogênico é um tipo de macro assinatura dos povos indígenas pré-coloniais, corrente nos sítios de agricultores, também denominado como mancha preta, considerado um corpo sedimentar remanescente de antigos solos de habitação e seu cinturão envoltório, depósitos de lixo, áreas de cocção de alimentos. Surge como manchas ovaladas de solo enegrecido pelo elevado teor de materiais biogênicos coletados, processados e descartados pelas comunidades précoloniais, rico em evidências arqueológicas, principalmente fragmentos de cerâmica e estruturas de combustão.

No caso do Sítio Piracanjuba foram coletados 15.288 fragmentos cerâmicos em quatro fundos de habitações e entornos: Núcleo de Solo Antropogênico 1 (NSA1), Núcleo de Solo Antropogênico 2 (NSA2), Núcleo de Solo Antropogênico 3 (NSA3), Núcleo de Solo Antropogênico 4 (NSA4), além de coleta de superfície e evidenciação de negativos de antigas estacas (FRANCO, 2007) (Figura 6). 

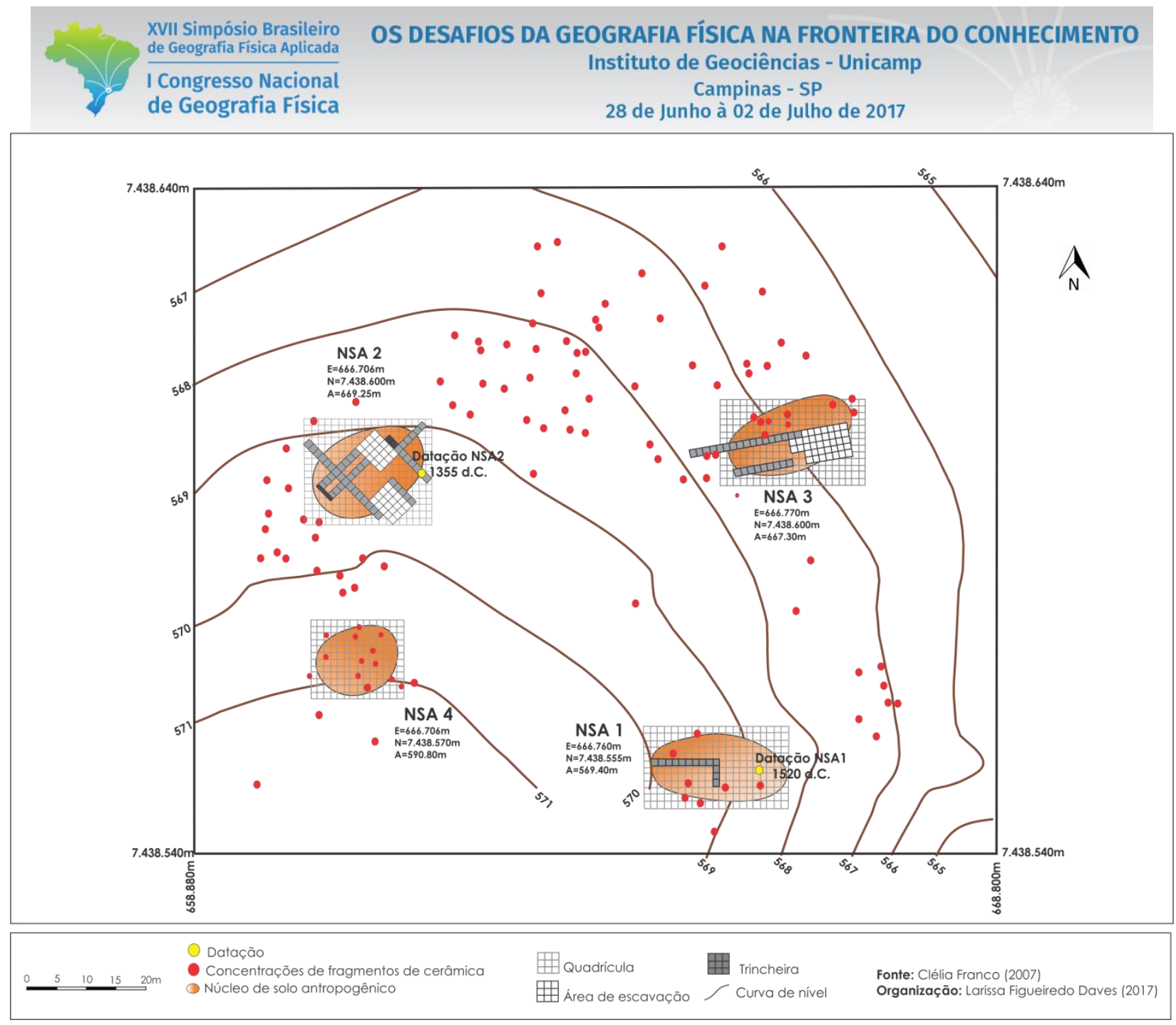

Figura 6: Representação das manchas pretas, intervenções realizadas e dispersão dos fragmentos cerâmicos do Sítio Arqueológico Piracanjuba.

O padrão de assentamento e a utilização da matéria-prima mostra que esses grupos habitavam áreas com poucas reservas litológicas aptas ao lascamento, pois tinham interesse e necessidade de confeccionar utensílios de cerâmica, o que os levou à procura de depósitos de argilas plásticas. Em alguns casos, porém, podem existir evidencias de sítios arqueológicos próximos aos fundos de vale próximo a cascalheiras aproveitáveis para a indústria lítica.

No caso, o fator arqueológico é verificado indiretamente, através da correlação e da interdigitação dos dados pré-históricos, topomorfológicos, geológicos e geomorfológicos, tais como: o reconhecimento dos afloramentos que serviram de fonte de matéria-prima para as populações pré-históricas, a identificação dos compartimentos favoráveis ao assentamento bem como a estreita dependência do assentamento em relação à fonte de matéria-prima. (MORAIS, 1986, p. 57) 
XVII Simpósio Brasileiro

de Geografia Física Aplicada

I Congresso Nacional

de Geografia Física
OS DESAFIOS DA GEOGRAFIA FÍSICA NA FRONTEIRA DO CONHECIMENTO

Instituto de Geociências - Unicamp

Campinas - SP

28 de Junho à 02 de Julho de 2017

A paisagem do Sítio Arqueológico Piracanjuba mostra que o ambiente está diretamente subordinado à ação do Rio Paranapanema, em cujo trecho a bacia é caracterizada por canal meândrico, marcado pela alta sinuosidade. A localização do sítio arqueológico na paisagem mostra que sua população ocupou a área de topo de colina e média alta vertente, próxima ao curso do Rio Paranapanema (Figura7).

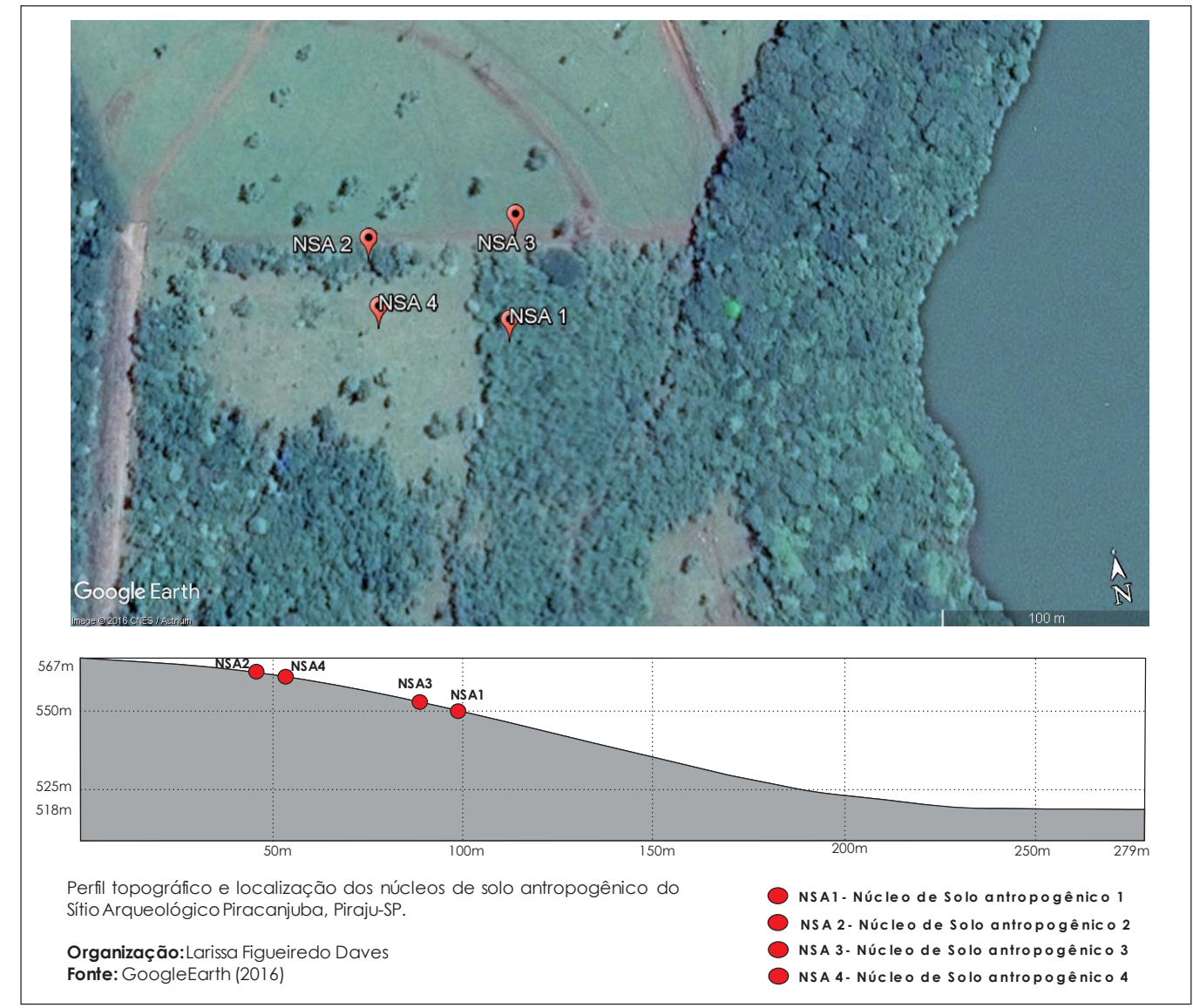

Figura 7: Perfil topográfico do sítio e a localização das manchas pretas.

A localização do sítio arqueológico no topo e média alta vertente da colina faz-nos levantar a hipótese de que no assentamento guarani foi desenvolvida a agricultura, pelo fato de haver grande concentração de fragmentos cerâmicos dispersos no perímetro do sítio. Outro fator é sua visibilidade em direção ao Rio Paranapanema, estratégia de proteção, caso invasores se aproximassem da aldeia.

Os guaranis promoviam manejo ambiental para fins de coleta e agricultura; a ligação entre o solo e vegetação era fundamental para sua subsistência, pois o tekoá ${ }^{3}$ era organizado por três espaços distintos: a vegetação circundante, as roças e a aldeia (NOELLI, 1993). As características físico-geográficas dessa região facilitaram a ocupação do grupo Guarani, pois "no vale do rio Paranapanema, cortado por

\footnotetext{
3 Tekoá- O termo tekoá, também grafado tekoha (pronunciado /tequô'á/), é de origem guarani e significa aldeia guarani. O significado completo da palavra, porém, não se reduz ao lugar habitado pelo grupo guarani.
} 
frequentes cachoeiras, os sítios se agregam nas imediações desses acidentes, que funcionam como ótimas armadilhas para peixes, facilitando a pesca" (PROUS, 1992, p. 376).

A unidade da morfologia de superfície apresenta topos de interflúvios planos a convexos (superfícies de derrames basálticos com expressivas capas eluviais), as vertentes são concâvas e convexas, com extensa exposição de basalto e arenitos silicificados associados aos complexos de rampa de colúvio; nos fundos de vale os depósitos quartenários areno-argilosos são resultantes de barramentos locais e/ou terraços aluviais com contribuições superficiais (às vezes interdigitadas) de colúvios não estratificados (compartimento favorável). (MORAIS, 1986)

A morfologia e a litologia do Rio Paranapanema condicionaram a forma de apropriação do espaço geográfico. A mesorregião denominada Província das Cuestas Basálticas, área onde o Sítio Arqueológico Piracanjuba está situado apresenta terraços ou superfícies inclinadas de depósitos colúvio-aluviais de baixa vertente, além de afloramentos de arenito intra-trapp. No âmbito da bacia, a província encontra-se balizada ao sul, pelas escarpas da Serra da Fartura, a leste corre o Rio Taquari e a oeste, o Rio Itararé. (MORAIS, 1986)

Segundo Morais (1986), está região apresenta a predominância de sítios líticos ocupados entre 1.000 e 7.000 anos antes do presente, com intenso aproveitamento dos arenitos silicificados como matéria-prima para a fabricação de artefatos de uso cotidiano. A região também teve a ocupação de sítios de grupos ceramistas, como é o caso do Sítio Arqueológico Piracanjuba.

Segundo Prous (1992), quando uma aldeia tem mais de três unidades residenciais, essas tendem a agruparse ao redor de uma "praça central"; no entanto, por vezes, duas casas vizinhas podem estar deslocadas para fora do círculo. Desse modo, verifica-se uma divisão do espaço em unidades distintas, enfatizadas pelos vestígios arqueológicos, como é o caso do Sítio Arqueológico Piracanjuba, principalmente pela concentração de vestígios no NSA 2 e 3.

A datação dos fragmentos cerâmicos mostra indícios de reocupação, pois no NSA1 a datação realizada em 2000 e a do NSA2 em 2004 apontam para os anos de 1520 d.C. e 1355 d.C., respectivamente, haja vista, que isso ocorre pela expansão e superdimensionamento da população na área do assentamento. Outro caso são os materiais líticos, encontrados no NSA 3, de peças como estilhas, lascas e núcleos confeccionados sobre seixos de silexito, provavelmente oriundos de cascalheiras do rio Paranapanema.

\section{CONSIDERAÇÕES FINAIS}

A interdisciplinaridade da Geografia e Arqueologia, sobretudo das Ciências denominadas da Terra "Geomorfologia e Geologia", contribuem para interpretação de transformações da paisagem, 
principalmente de antigas habitações indígenas que deixaram no solo a marca do passado e de seus vestígios arqueológicos.

A análise da paisagem por meio da metodologia de Geoarqueologia permitiu interpretar a relação existente entre a localização do sítio arqueológico, distribuição dos vestígios arqueológicos e padrão de assentamento guarani na área do Sistema de ocupação indígena da área do Médio Paranapanema, lado paulista. Assim, a discussão do padrão de assentamento do grupo guarani e a descrição da morfologia do relevo na região Piraju foram fundamentais para tal análise.

A datação dos fragmentos cerâmicos mostraram indícios de reocupação, pois no núcleo de solo antropogênico (NSA1) e núcleo de solo antropogênico (NSA2) do sítio arqueológico analisado em tela, apontam para os anos de 1520 d.C. e 1355 d.C. respectivamente, ocorrendo uma disparidade. Diante disso, levantamos a hipótese de que o grupo guarani que habitou sítio arqueológico estudado em tela, em tempos pretéritos, desenvolvia o manejo de agricultura, pelo fato da grande concentração de fragmentos cerâmicos dispersos no perímetro do sítio e sua localização (topo e média alta vertente da colina), o que nos leva à hipótese de reocupação.

\section{REFERÊNCIAS}

AB'SABER, A. N. Uma revisão do quaternário paulista: do presente para o passado. Revista Brás de Geografia, 1969 , p. 1-50.

ANGELUCCI, D.E. A partir da terra: a contribuição da geoarqueologia. In MATEUS, J.; MORENO-GARCÍA, M., eds. - Paleoecologia humana e arqueociências: um programa multidisciplinar para a arqueologia sob a tutela da cultura. Lisboa: Instituto Português de Arqueologia (Trabalhos de Arqueologia;29), p. 35-84, 2003.

BERTRAND; BERTRAND. Uma Geografia Transversal e de Travessias: o meio ambiente através dos territórios e das temporalidades. Editora Massoni, Maringá, PR, 2009.

BOADO, F. C.; RODRIGUEZ, B. N.; LANDIN, D. C.; VÁZQUEZ, M. D. et al. Arqueología del Paisaje. El área Bocelo-Furelos entre los tiempos Paleolíticos y Medievales (Campañas de 1987, 1988 y 1989), vol. 6, 1991, p. 35.

BUTZER, K. W. Archaeology as human ecology: Method and theory for a contextual approach, 1982, p. 1-348.

CARR, C. The Nature of O rganization of Intrasite Archaeological Records and Spatial Analytic Approaches to their Investigation. Advances in Archaeological Method and Theory, 7 New York, 1984, Academic Press: $103-222$.

CASSETI, V. A natureza e o espaço geográfico. In: MENDONÇA, F. A.; KOZEL, S. (Org.). Elementos de Epistemologia da Geografia Contemporânea. Curitiba - PR: Editora UFPR, p. 145-163, 2009.

CLAVAL, P. Epistemologia da Geografia. Florianópolis: Editora. UFSC, 2014.

GLADFELTER, B.G. Geoarchaeology: The Geomorphologist and Archaeology. American Antiquity, 42 (4): $519-$ $538,1977$. 
GLADFELTER, B. G.(1981) - Developments and Directions in Geoarchaeology. In SCHIFFER, M.B., ed. Advances in Archaeological Method and Theory, 4, p. 343-364.

GONZALEZ, M. M. B.; PIEDADE, S. C.; MORAIS, J. L. Arqueofauna do Sítio Piracanjuba, Piraju-SP. Revista do Museu de Arqueologia e Etnologia, São Paulo 17:231-249, 2007.

HASSAN, F. Geoarchaeology: The Geologist and Archaeology. Source: American Antiquity, vol. 44, nº. 2, 1979, p. $267-270$

FACCIO, N. B. Arqueologia Guarani na Área do Projeto Paranapanema: estudo dos sítios de Iepê, SP. Volume I. Tese de Livre Docência - Museu de Arqueologia e Etnografia, Programa de Pós-Graduação em Arqueologia Universidade de São Paulo, São Paulo, 2011.

FRANCO, C. Visão sistêmica do Sítio Arqueológico Piracanjuba: a descoberta de conhecimento em sítios arqueológicos. Tese de Doutorado, UNESP/FCT- Campus de Presidente Prudente, Presidente Prudente, 2007, p. 14.

MORAIS, J. L. A Propósito da Interdisciplinaridade em Arqueologia. Revista do Museu Paulista, Editora da Universidade de São Paulo, São Paulo, v. XXXII, p. 155, 1986.

Plano cartográfico do Projeto Paranapanema, São Paulo, 1995. 10:3-30.

. Tópicos de Arqueologia da Paisagem. Revista do Museu de Arqueologia e Etnologia, São Paulo, 2000,

Arqueologia da Região Sudeste. Revista da USP, n. 44, 194-217, 1999/2000.

NOELLI, Francisco Silva. Sem Tekoha não há Tekó: em busca de um Modelo Etnoarqueológico da Aldeia e da Subsistência Guarani e sua aplicação a uma área de domínio no Delta do Jacuí - RS. Porto Alegre. Dissertação de Mestrado PUC-RS, 1993.

PASSOS, M. M. A Raia Divisória: geossistema, paisagem e eco-história. Maringá: Eduem, 2006.

PASSOS, M. M. Biogeografia e Paisagem. 2a ed. Presidente Prudente: UNESP - PPGE, 2a Edição, 2003.

PANACHUK, L.; CARVALHO, A.; JÁCOME, C.; et. al. Reflexões sobre as aldeias Tupiguarani: apontamentos metodológicos. In: Prous, A.; Lima, T. A. (Orgs.). Os ceramistas Tupiguarani: eixos temáticos. Belo Horizonte: IPHAN, v. 3, 2010.

TRIGGER, B. G., História do pensamento arqueológico. Tradução de Ordep Trindade Serra. São Paulo: Odysses Editora, 2004.

WATERS, M. R. Principles of geoarchaeology. A North American perspective. Tucson: The University of Arizona Press, 1992. 


$\begin{aligned} & \text { XVII Simpósio Brasileiro } \\ & \text { de Geografia Fisica Aplicada }\end{aligned}$
$\begin{aligned} & \text { I Congresso Nacional } \\ & \text { de Geografia Física }\end{aligned}$

Laboratório de Arqueologia Guarani e Estudos da Paisagem (LAGEP) - FCT UNESP Campus de Presidente Prudente. Bolsista de Mestrado do CNPq (Conselho Nacional de Desenvolvimento Cientifico e Tecnológico). 